\title{
Hormonal Characteristics of the Human Menstrual Cycle throughout Reproductive Life
}

\author{
Barry M. Sherman and Stanley G. Korenman \\ From the Division of Endocrinology, Department of Internal Medicine, \\ University of Iowa and Veterans Administration Hospitals, \\ Iowa City, Iowa 52242
}

A в S T R A C T The changes in serum levels of luteinizing hormone $(\mathrm{LH})$, follicle-stimulating hormone $(\mathrm{FSH})$, estradiol, and progesterone that occur both early and late in reproductive life were characterized and compared with findings in young, normal women and in patients with certain menstrual disorders.

A total of 50 complete menstrual cycles in 37 women were examined. Five distinct patterns of hormonal regulation were found, three of which are reported here: (a) A long follicular phase and delayed follicular maturation in young women with long, unpredictable intermenstrual intervals from menarche; $(b)$ a short follicular phase with increasing age and in short cycles in perimenopausal women; and $(c)$ true anovulatory vaginal bleeding in long cycles in perimenopausal women.

The short cycles before and during the menopausal transition were found to have lower $E_{2}$ levels and high $\mathrm{FSH}$ concentrations throughout, while $\mathrm{LH}$ remained in the normal range. During long cycles in perimenopausal women, concentrations of $\mathrm{LH}$ and $\mathrm{FSH}$ were in the menopausal range. However, follicular maturation was observed months after high levels of gonadotropins were attained.

These studies permit the characterization of the menstrual history of the normal woman in terms of the hormonal changes that occur and provide a basis for the definition of several disorders of follicular maturation.

\section{INTRODUCTION}

Irregular patterns of menstruation are common in some women at all times of reproductive life. In large popu-

Dr. Korenman's present address is Department of Internal Medicine, UCLA School of Medicine, Veterans Administration Hospital, Sepulveda, Calif. 91343.

Received for publication 11 May 1974 and in revised form 25 November 1974.

The Journal of Clinical Investigation Volume 55 April 1975.699-706 lations studied prospectively, variability in cycle length has been shown during the years that immediately follow menarche and precede menopause (1). The pattern of vaginal bleeding after menarche is often characterized by long intermenstrual intervals. Between the ages of 25 and 40, cycle length is regular, and there is a gradual decrease in total cycle length until the menopausal transition. Before menopause, the pattern of vaginal bleeding again becomes irregular, long intervals, often alternating with unusually short cycles (1).

Analysis of hormonal regulation of the human menstrual cycle by measurement of circulating pituitary and ovarian hormones has, to date, been limited to young women with regular cycle $(2-10)$ or to clinically abnormal cycles (11-17). We have measured serum levels of serum luteinizing hormone $(\mathrm{LH}),{ }^{1}$ folliclestimulating hormone $(\mathrm{FSH})$, estradiol $\left(\mathrm{E}_{2}\right)$, and progesterone $(\mathrm{P})$, throughout the cycles of women at the extremes of menstrual experience and compared the findings with those in young and middle-aged normal women and in certain menstrual disorders previously reported $(16,17)$.

Long cycles in young women of normal body weight were characterized by delayed follicular maturation and hormonal changes suggesting normal ovulation. In older women, decreased cycle length was due to a short follicular phase. In regularly menstruating premenopausal women there was hormonal evidence of follicular maturation and corpus luteum function with a significant decrease in length of the follicular phase, diminished $\mathrm{E}_{2}$ concentrations, and striking increases in the concentration of FSH throughout the cycle. During long cycles in perimenopausal women, levels of $\mathrm{LH}$ and $\mathrm{FSH}$ were in the menopausal range and vaginal bleeding occurred in the absence of follicular maturation

1 Abbreziations used in this paper: $\mathrm{E}$, estradiol ; $\mathrm{FSH}$, follicle-stimulating hormone; LH, luteinizing hormone: P. progesterone. 
or after follicular maturation and subnormal corpus luteum $\mathrm{P}$ secretion. In one individual, long, anovulatory cycles were followed by a short cycle showing fluctuations in hormone levels characteristic of follicular maturation and corpus luteum formation.

These findings provide endocrine correlations to epidemiologic observations of menstrual cycle length throughout reproductive life (1). Early variability in cycle length appears to be due to delayed follicular maturation. The general decrease in cycle length in later reproductive life is attributable to a shorter follicular phase, which in premenopausal women is accompanied by a striking increase in $\mathrm{FSH}$ and significantly decreased $E_{2}$ levels throughout the cycle. The variable pattern of vaginal bleeding that may occur during the menopausal transition is, like the menarchial transition, attributable to irregular follicular maturation. Very short cycles, associated with hormonal changes characteristic of follicular maturation, are interspersed among unusually long cycles that show no signs of corpus luteum formation.
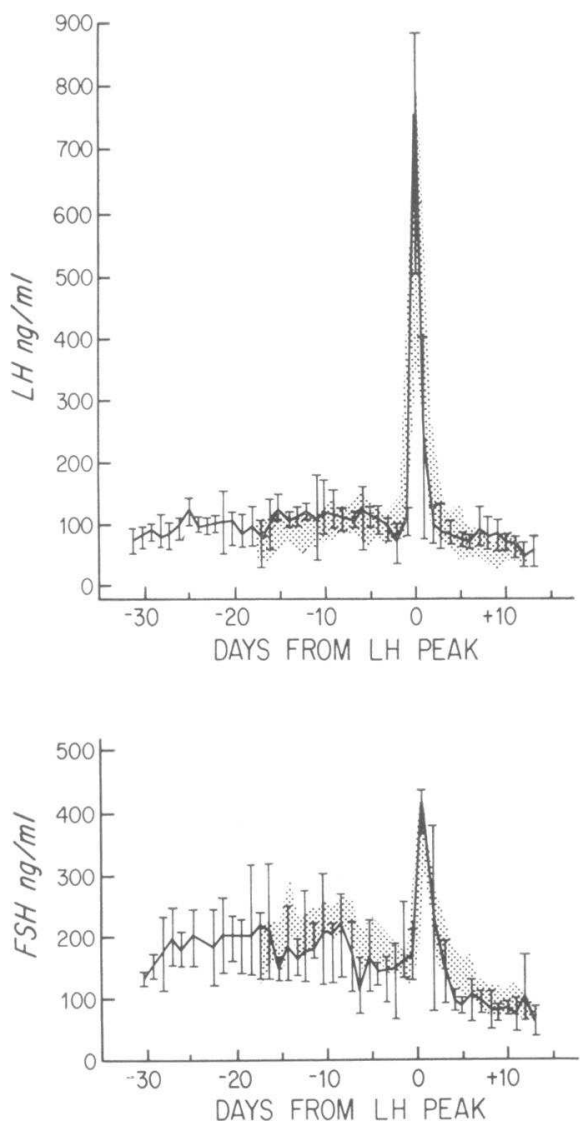

\section{METHODS}

Subjects. Students in the College of Nursing, nurses, employees of University Hospital, and patients of the Endocrinology Clinic were asked to serve as paid volunteers for studies of homonal correlations of the menstrual cycle. A detailed menstrual history was obtained, and blood samples were obtained daily on an outpatient basis during at least one complete cycle. Each subject was maintained on ferrous sulfate, experienced no reduction of hematocrit, and pursued normal activities during the study.

10 subjects, age 18-30, with histories of regular menstruation, who had cycles demonstrating an early follicular phase increase in $\mathrm{FSH}$, a preovulatory $\mathrm{LH}$ peak, a luteal phase of at least 11 days, a luteal phase $\mathrm{P}$ peak greater than $10 \mathrm{ng} / \mathrm{ml}$, and a biphasic basal body temperature record, constituted the reference group. 16 women who had blood drawn during a total of 19 cycles constituted the experimental group. They could be divided into four categories.

(a) One cycle was studied in each of four normal-weight subjects, age 18-21, who gave histories of long intermenstrual intervals from time of menarche. (b) One cycle was examined in each of five women, age 40-41, with histories of regular menses. Three were parous, and two were nulliparous. (c) Six cycles were examined in six women, age 46-51, who had regular menses and no menopausal symp-
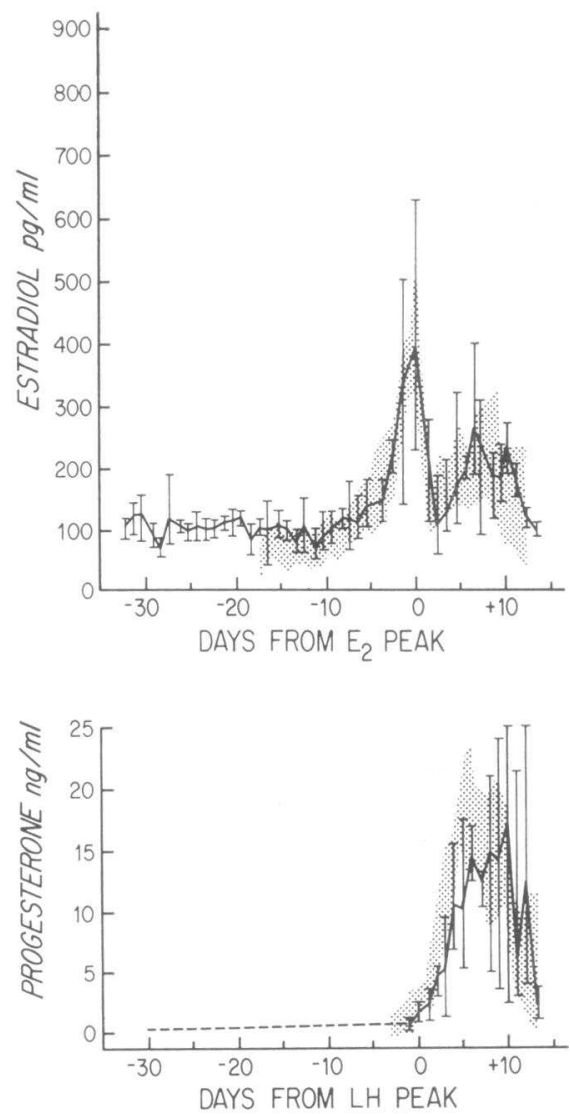

Figure 1 The mean and range of serum $\mathrm{LH}, \mathrm{FSH}, \mathrm{E}_{2}$, and $\mathrm{P}$ in four women, age 18-21, with infrequent menses are compared with the mean \pm 2 SEM in 10 cycles in women age 18-30 (shaded area). LH, FSH, and $\mathrm{P}$ levels are synchronized around the day of the LH peak, and $E_{2}$ levels are synchronized around the day of the $E_{2}$ peak. 

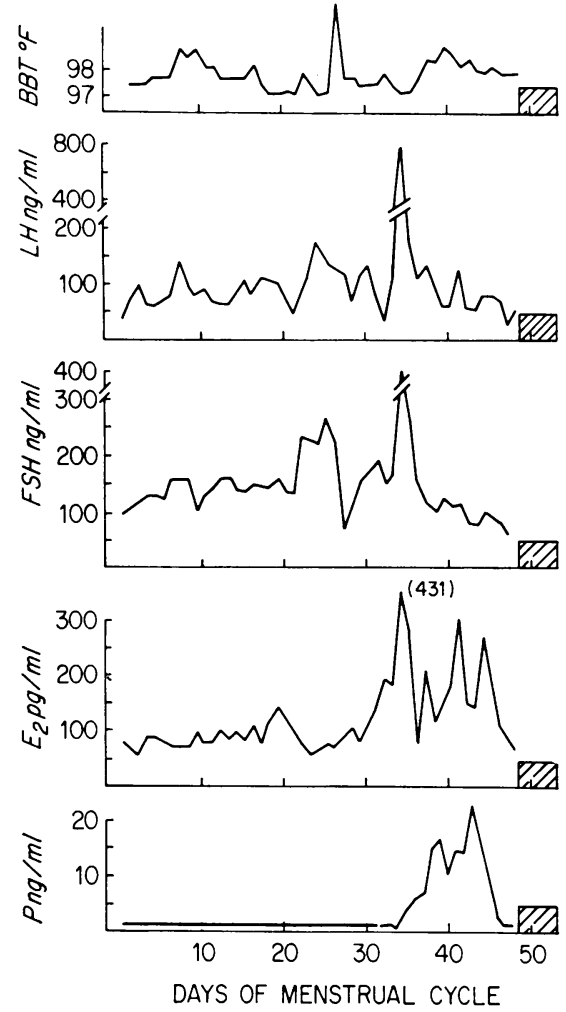

Figure 2 Daily concentrations of serum LH, FSH, $E_{2}$, and $\mathrm{P}$ and basal body temperature (BBT) in one subject, age 19 , with infrequent menses. The cycle is synchronized around the day of the LH peak. The hatched area indicates menstruation.

toms. Three were aware that cycle length had decreased in recent years. Four were parous, and two were nulliparous (4). In one of these women, hormone analysis was carried out during the last 54 days of a subsequent cycle of more than 3 mo duration. Another woman, age 49, maintained a menstrual calendar from age 40 . Long cycle intervals, unaccompanied by menopausal symptoms, began at age 48. Homone analysis was done during cycles of 63 , 53 , and 27 days.

Methods. Serum was stored at $-20^{\circ} \mathrm{C}$, and each cycle was assayed as a unit so that fluctuations would represent intra- rather than interassay variation. The serum FSH and $\mathrm{LH}$ were measured by radioimmunoassay in a standard double-antibody system utilizing reagents supplied by the National Pituitary Agency $(18,19)$. Results were expressed as nanograms per milliliter of the reference preparation LER 907. $\mathrm{P}$ and $\mathrm{E}_{2}$ were measured with antisera generously supplied by Dr. Gordon Niswender, and activated charcoal was used to separate bound from free steroid. The $\mathrm{E}_{2}$ method employed a specific antiserum and a simple ether extraction of serum (20).

\section{RESULTS}

The values for $\mathrm{LH}, \mathrm{FSH}, \mathrm{E}_{2}$, and $\mathrm{P}$ in 10 women, age 18-30, shown in the shaded area of Figs. 1, 3, and 4, were not different from those described by others for women in this age group (2-9). In each instance FSH,
TABLE I

Characteristics of Menstrual Cycle Length in Normal Women throughout Reproductive Life and in Disorders of Follicular Maturation

\begin{tabular}{lccc}
\hline \multicolumn{1}{c}{ Group } & $\begin{array}{c}\text { Follicular } \\
\text { phase }\end{array}$ & $\begin{array}{c}\text { Luteal } \\
\text { phase }\end{array}$ & $\begin{array}{c}\text { Total cycle } \\
\text { length }\end{array}$ \\
\hline & days & days & days \\
Age 18-30 & $16.9 \pm 3.7$ & $12.9 \pm 1.8$ & $30.0 \pm 3.6$ \\
Age 40-41 & $10.4 \pm 2.9$ & $15.0 \pm 0.9$ & $25.4 \pm 2.3$ \\
Age 46-51 & $8.16 \pm 2.8^{*}$ & $15.9 \pm 1.3$ & $23.2 \pm 2.9$ \\
Long follicular phase & $33.0 \pm 2.2$ & $14.2 \pm 2.2$ & $47.2 \pm 4.3$ \\
Short luteal phase & $17.2 \pm 1.7$ & $7.0 \pm 2.4^{*}$ & $24.2 \pm 3.6$ \\
Inadequate luteal phase & $71.6 \pm 50.5^{*}$ & $12.3 \pm 0.5$ & $84.0 \pm 50.6^{*}$ \\
& & & \\
\hline
\end{tabular}

Results are means $\pm \mathrm{SD}$

$* P=<0.05$.

$\ddagger$ Follicular phase is from first day of menses to the LH peak.

$\S$ Luteal phase is from $\mathrm{LH}$ peak to onset of menses.

$\mathrm{LH}$, and $\mathrm{P}$ secretion were oriented with regard to the LH peak, designated day $0 . \mathrm{E}_{2}$ values were oriented by the $\mathrm{E}_{2}$ peak because of the known variability in the relationship between the $\mathrm{E}_{2}$ and $\mathrm{LH}$ peaks (10).

In each of the experimental groups the mean and range of values for each day are compared with the reference population. It must be emphasized that the range given encompasses a group of cycles and that in
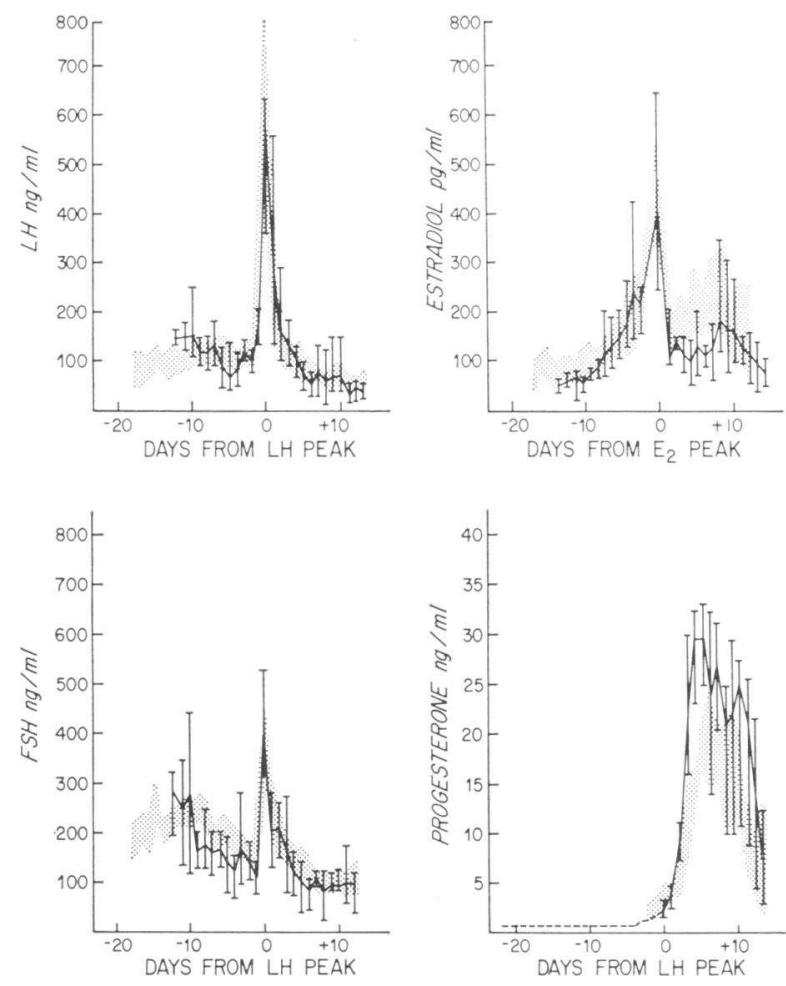

Figure 3 The mean and range of serum LH, FSH, E. and $\mathrm{P}$ in five women, age $40-41$, are compared to the mean \pm 2 SEM in 10 cycles in women aged $18-30$. The data are illustrated as in Fig. 1. 

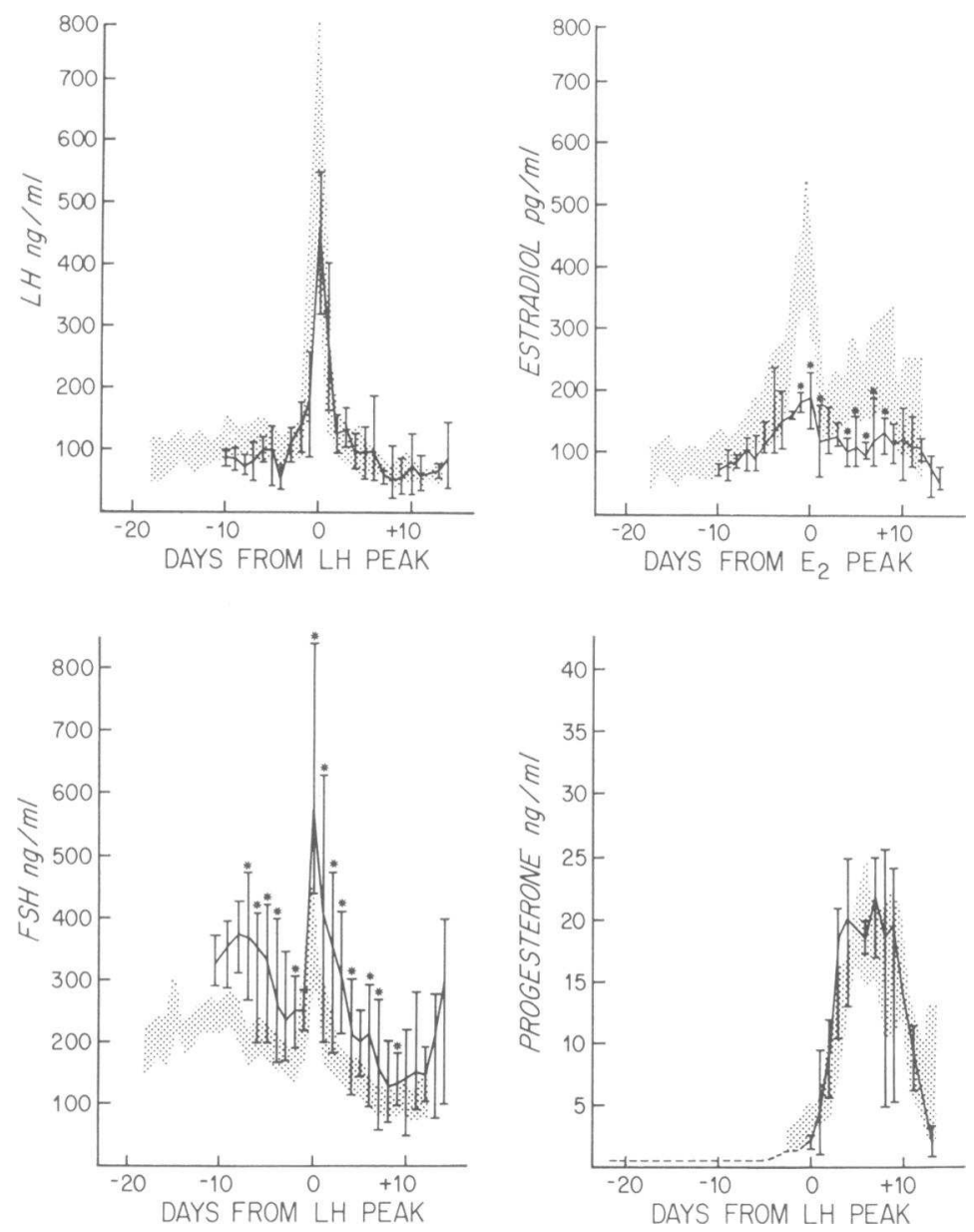

FIGURE 4 The mean and range of serum LH, FSH, $\mathrm{E}_{2}$, and $\mathrm{P}$ in six premenopausal women with regular menses are compared with the mean \pm 2 SEM in 10 cycles in women aged 18-30. The data are illustrated as in Fig. 1. An asterisk $(*)$ indicates a statistically significant difference between the values of the two groups, $P=<0.05$.

no case were a series of extreme values, high or low, derived from a single patient.

The mean and range of hormone values in four long cycles obtained from four normal-weight women, age 18-21, with infrequent menstruation from the time of menarche, are shown in Fig. 1. In each case an indeterminately long follicular phase was followed by changes in hormone concentrations indicative of follicular maturation, ovulation, and corpus luteum function identical to those observed in the normal cycles. The increased cycle length was always due to a prolonged follicular phase of the cycle as measured by the time before the LH peak (Table I). During the prolonged follicular phase, $E_{2}$ levels were $70-110 \mathrm{pg} / \mathrm{ml}$, $\mathrm{LH}$ and $\mathrm{FSH}$ were in the range observed during the normal follicular phase, and $\mathrm{P}$ was less than $1 \mathrm{ng} / \mathrm{ml}$. In two of these cycles the maturation of a follicle was preceded by a rise of $\mathrm{FSH}$ comparable to that seen during the early follicular phase of many normal-length cycles. This increase in FSH occurred during days 2025 of the cycle illustrated in Fig. 2. The FSH rise was not sustained and, as in the normal group, fell slightly with follicular maturation.

In the women age 40-41, hormone values did not differ from those observed in the younger subjects (Fig. 3). The decrease in mean cycle length (25.4 days) compared to the younger women (30.0 days) was attributable to a shorter interval between the onset of menses and the $\mathrm{LH}$ peak. The duration of time necessary for the follicle to complete its maturation, as characterized by the exponential rise in estradiol secretion, was no different in the two groups.

The six premenopausal women, age 46-51, had cycles shorter in total length (mean 23.3 days) than women 18-21 (Table I, Fig. 4). This was attributable to a shortened follicular phase of 4-13 (mean 8.3) days. By 
contrast, the luteal phase, as measured from the LH peak to the onset of menses, was 10-16 (mean 13.0) days, and $\mathrm{P}$ levels were not different from those observed in younger women (Fig. 4). The $\mathrm{E}_{2}$ concentration during the early follicular phase was $70-110$ $\mathrm{pg} / \mathrm{ml}$, while the mean midcycle peak, $192 \mathrm{pg} / \mathrm{ml}$, and the mean maximal luteal phase concentration, $157 \mathrm{pg} /$ $\mathrm{ml}$, were significantly lower than observed in the younger women $(P=<0.05)$. It was of particular interest that the serum FSH was strikingly increased throughout the cycle, despite the attainment of levels of $E_{2}$ that might be expected to suppress its secretion, while LH remained indistinguishable from normal.

Fig. 5 illustrates the daily hormone levels during two cycles in one of the 50-yr-old subjects. When the first cycle was studied, there had been no change in the pattern of vaginal bleeding, and she demonstrated the elevated FSH levels seen in this group. Blood sampling was resumed 4 mo later during her first unusually long intermenstrual interval, and both $\mathrm{LH}$ and $\mathrm{FSH}$ were in the menopausal range. It was of note that hormonal changes associated with follicular maturation ensued even at high gonadotropin concentrations. Vagi-
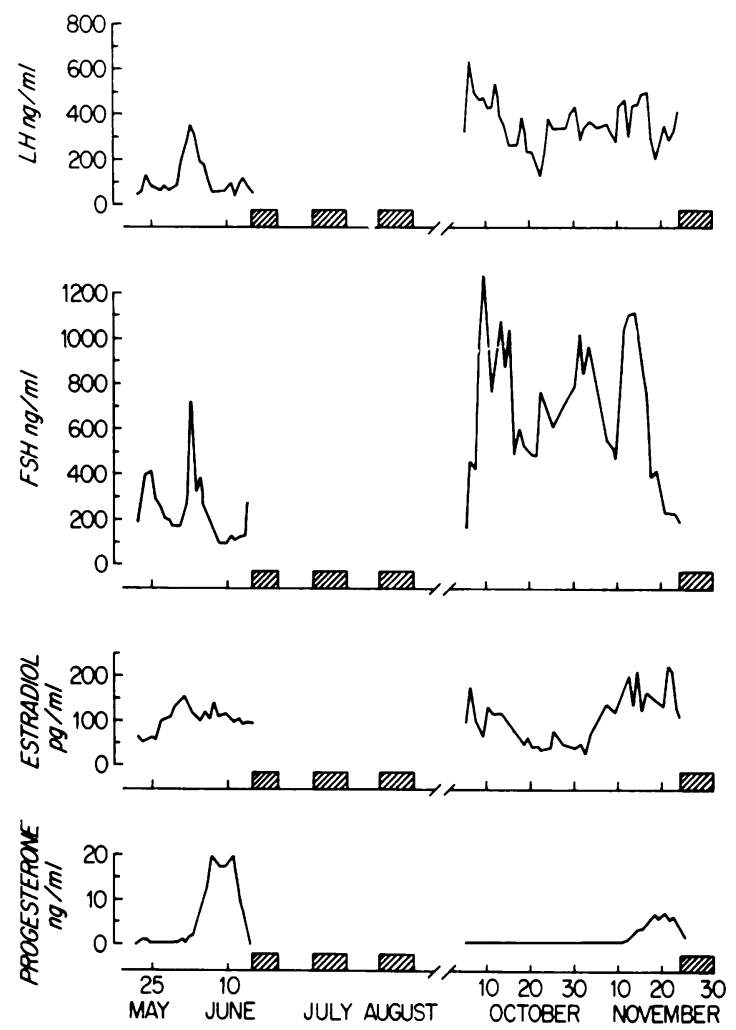

Figure 5 Concentrations of $\mathrm{LH}, \mathrm{FSH}, \mathrm{E}_{2}$, and $\mathrm{P}$ during two cycles in one 50-yr-old subject. Hormone levels are arrayed by calendar date, and the hatched areas indicate menstruation.
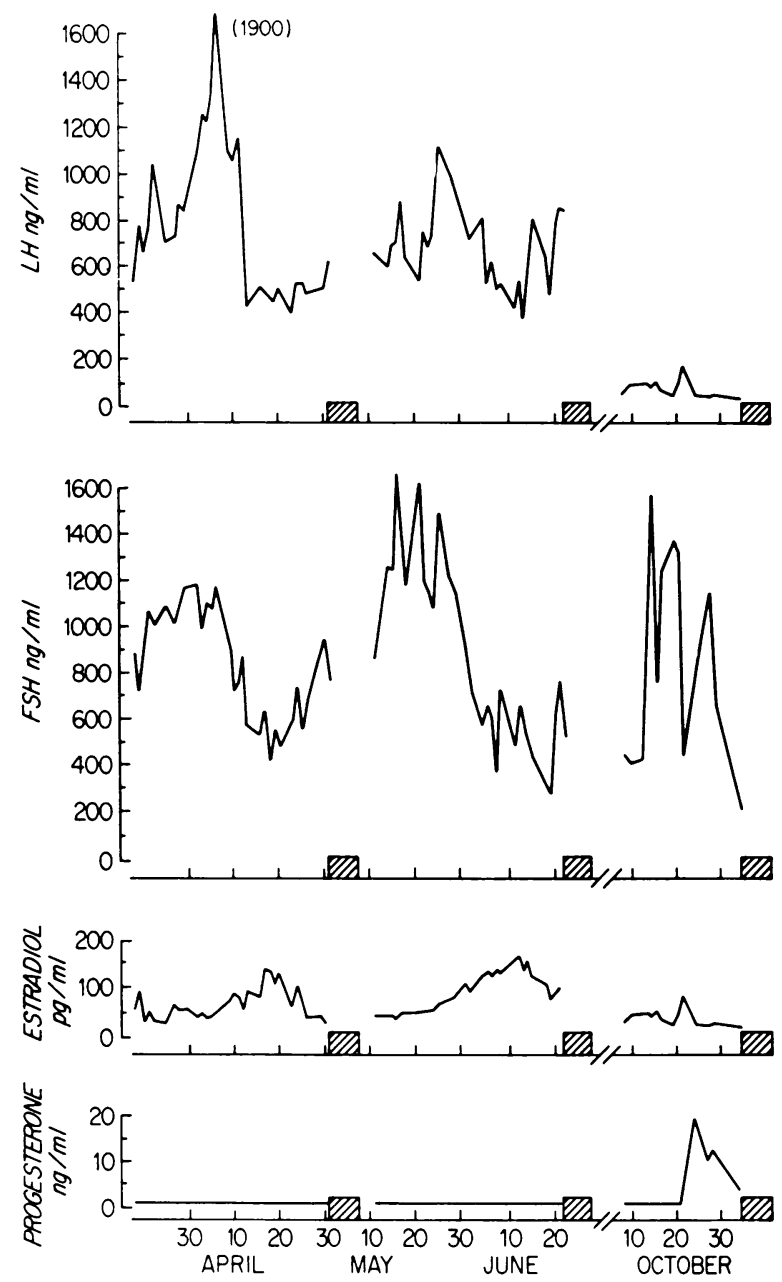

Figure 6 Daily concentrations of serum LH, FSH, $\mathrm{E}_{2}$, and $\mathrm{P}$ during three cycles in one 49-yr-old subject. Hormone levels are arrayed by calendar date, and the hatched area indicates menstruation.

nal bleeding followed a progressive rise in $\mathrm{E}_{2}$ and a sustained increase in serum $\mathrm{P}$. The concentrations of $\mathrm{P}$ did not exceed $10 \mathrm{ng} / \mathrm{ml}$, typical of the previously described inadequate luteal phase (17).

A 49-yr-old woman kept a menstrual calendar for $9 \mathrm{yr}$, during which mean cycle length was 28.0 days. She began to experience unusually long intermenstrual intervals, and studies done during cycle of 63 and 53 days showed $\mathrm{LH}$ and FSH levels greater than $600 \mathrm{ng} /$ $\mathrm{ml}$ (Fig. 6). Basal $\mathrm{E}_{2}$ levels of $30-50 \mathrm{pg} / \mathrm{ml}$ increased to peaks of $125-150 \mathrm{pg} / \mathrm{ml}$, accompanied by reciprocal, proportionate suppression of $\mathrm{LH}$ and $\mathrm{FSH}$. The $\mathrm{P}$ concentration was always less than $1 \mathrm{ng} / \mathrm{ml}$, and vaginal bleeding occurred after a period of increased $E_{2}$ secretion. A subsequent cycle of 27 days in the same subject demonstrated evidence of follicular maturation and luteinization. The $\mathrm{E}_{2}$ concentration increased from 
less than $20 \mathrm{pg} / \mathrm{ml}$ to a maximum of $115 \mathrm{pg} / \mathrm{ml}$ at midcycle, while the $P$ level rose from less than $1 \mathrm{ng} / \mathrm{ml}$ to $19 \mathrm{ng} / \mathrm{ml}$ during days $17-19$. LH concentrations were in the normal range throughout the cycle, while FSH remained elevated, with maximum levels of $1,500 \mathrm{ng} / \mathrm{ml}$ falling to a low of $200 \mathrm{ng} / \mathrm{ml}$ at the end of the luteal phase. Thus an anovulatory cycle was followed by a cycle that demonstrated evidence of follicular maturation.

\section{DISCUSSION}

These studies were based on the monumental prospective study of menstrual cycle length reported by Treloar, Boynton, Benn, and Brown, which showed that the 5-7 yr after menarche and 6-8 yr before menopause were characterized by wide variability in cycle length and contrasted with the years from 20 to 40 , during which cycle length was regular and there was a gradual decrease of 2-3 days in mean cycle length (1). We have described the endocrinologic features of menstrual cycles at the extremes of reproductive life and compared them with cycles in regularly menstruating young women and with abnormal cycles recently reported.

Long cycles during the menarchial transition were characterized by delayed but completely normal follicular maturation, including basal body temperature records (Figs. 1 and 2, Table I). Although the study of the menstrual cycles in the years immediately after menarche could not be done because of the necessity for frequent blood samples, the four young women reported here all had histories of irregular menses from the time of menarche.

In regularly menstruating women, age 40-41, the hormonal features of follicular maturation and corpus luteum function were not different from those of younger women (Fig. 3, Table I). The slightly shorter

TABLE II

A Classification of Menstrual Cycles

\begin{tabular}{lll}
\hline \multicolumn{1}{c}{ Name } & Illustrated & \multicolumn{1}{c}{ Clinical features } \\
\hline Long follicular phase & Figs. 1, 2 & $\begin{array}{c}\text { Long cycles in young women } \\
\text { of normal weight. } \\
\text { Short or normal-length cycles: } \\
\text { may be associated with } \\
\text { infertility. }\end{array}$ \\
Inadequate luteal phase & Fig. 5 (17) & $\begin{array}{c}\text { Cycles of variable length } \\
\text { found in oligomenorrheic, } \\
\text { obese women in the } \\
\text { presence or absence of } \\
\text { hirsutism and during the } \\
\text { menopausal transition. }\end{array}$ \\
Short follicular phase & Figs. 3-5 & $\begin{array}{c}\text { Progressively short, ovulatory } \\
\text { cycles with age. }\end{array}$ \\
Anovulatory & Fig. 6 & $\begin{array}{c}\text { Long cycles during meno- } \\
\text { pausal transition. }\end{array}$ \\
\hline
\end{tabular}

cycle length was in all cases attributable to a reduced interval between the first day of menses and the midcycle gonadotropin peak.

In contrast to the delayed follicular maturation in young women, regularly menstruating premenopausal women, age $46-51$, often had short cycles also attributable in all cases to decreases in the time preceding hormonal evidence of follicular maturation. In these women, early follicular phase $E_{2}$ levels were not different from those in younger women. The lower midcycle and luteal phase $\mathrm{E}_{2}$ concentrations must reflect decreased secretion by the maturing follicle and corpus luteum, since the metabolic clearance rate of $E_{2}$ is not different in pre- and postmenopausal women (21). This contrasts with corpus luteum $\mathrm{P}$ secretion, which was usually equal to that found in the younger women.

Long cycles during the menopausal transition women were terminated by an inadequate luteal phase or by an episode of vaginal bleeding that followed a simple decline in $\mathrm{E}_{2}$ concentration without hormonal evidence of ovulation or corpus luteum formation and in the presence of menopausal levels of gonadotropins, i.e., truly anovulatory cycles. The long cycles with high gonadotropin concentrations did not necessarily indicate the absence of follicles, because at least in one instance a short cycle demonstrating hormonal changes associated with follicular maturation and corpus luteum function followed long, anovulatory cycles (Fig. 6).

We have recently reported a luteal phase of 10 days or less in four women who volunteered as normal subjects (16). In two subjects a short luteal phase was found to occur repeatedly in four cycles analyzed over $1 \mathrm{yr}$. Luteal phase progesterone levels were uniformly low, the mean $\mathrm{E}_{2}$ peak was significantly below normal, and there was no $\mathrm{E}_{2}$ rise during the short luteal phase. FSH did not demonstrate the follicular phase increase observed during normal cycles and was significantly less than found in normal cycles during days -9 and -10 .

Nine cycles of 24-157 days were studied in seven obese women, three of whom were hirsute (17). All sought medical attention because of irregular menses. In each case menstruation was preceded by hormonal changes associated with follicular maturation and corpus luteum formation. Although in all nine cycles the luteal phase was of more than 10 days duration, $\mathrm{P}$ concentrations were uniformly low. The $\mathrm{E}_{2}$ peak and luteal phase $\mathrm{E}_{2}$ concentrations were not different from normal. However, as in short luteal phase cycles, FSH during follicular phase days -8 through -11 was significantly less than normal, while $\mathrm{LH}$ levels exhibited a normal pattern.

On the basis of these studies we propose a new classification for some clinical patterns of normal and abnormal vaginal bleeding (Table II). It is an initial 
attempt to describe abnormalities of the menstrual cycle based on disorders of hormonal regulation.

A remarkable feature of the data in the perimenopausal women (Figs. 4-6) indicated that when $\mathrm{LH}$ was in the normal range for the cycle stage, FSH levels were consistently elevated in over 400 individual measurements. There are multiple possible interpretations of this finding, including differential regulation of FSH and $\mathrm{LH}$ secretion during diminished $\mathrm{E}_{2}$ concentration at the hypothalamic or pituitary level or differential sensitivity to gonadotropin-releasing hormone.

These data have led us to hypothesize an ovarian regulatory hormone, an inhibin, which would exert a negative feedback control over FSH secretion and which would be reduced in the years before menopause, consequent to a diminished number of follicles. We have not been able to find a previous reference to this possibility.

There are several lines of evidence supporting the presence of an inhibin. First, during menopause, $\mathrm{FSH}$ and LH appear to change proportionally when estrogen is given (22-24), and the two appear to rise proportionately after castration (25-26). A similar proportional fall in gonadotropins was noted with the spontaneous rise in $E_{2}$ during the two anovulatory cycles of Fig. 6. Therefore, a factor other than the concentration of $\mathrm{E}_{2}$ must be involved to produce the dissociation of $\mathrm{FSH}$ and $\mathrm{LH}$ levels seen in the older women. An important recent study has indicated that the presence or absence of ovarian follicles in women with primary or secondary amenorrhea can be predicted accurately by the level of FSH in the serum (27). The absence of follicles resulted in a substantial increase in the $\mathrm{FSH}$ concentration regardless of the diagnosis. Although the exceedingly complex events controlling the concentration and changes in concentration of the two gonadotropins during the follicular phase of the normal menstrual cycle have been explained by differential effects of estrogen at the hypothalamus and pituitary (28), the data are also compatible with the presence of another inhibitory regulator of $\mathrm{FSH}$ secretion that increases with follicular maturation.

Analogy with data in men provides additional support for the hypothesis. There are no sexually unique hormones, although there are wide variations in the secretion of hormones related to reproduction. Evidence for inhibin in the male is accumulating (29-32), and it has been invoked to account for high levels of FSH and normal levels of LH in oligospermic males (33-35), after testicular irradiation and after cytotoxic chemotherapy $(36,37)$.

From the viewpoint of physiological need, an inhibin would be an important mechanism for controlling the number of follicles that mature each cycle and would be of special importance in higher species, where the number of conceptuses supportable during a gestation is limited. Finally, the presence of inhibin may aid our interpretation of certain disorders of reproductive function.

From longitudinal studies of the levels of FSH, LH, $\mathrm{E}_{2}$, and $\mathrm{P}$ during normal menstrual cycles throughout reproductive life and in association with certain types of clinical abnormalities, we have suggested a partial classification of menstrual cycle abnormalities (Table II) and have hypothesized the presence of a hormonal control mechanism in women analogous to the inhibin proposed for men.

\section{ACKNOWLEDGMENTS}

We are indebted to Joanne Ham, Leslie Carpenter, and Gail Gahn for superior technical assistance and to the staff of the Clinical Research Center for their aid in executing these studies.

To the women who participated in these studies, we owe special thanks.

This work was supported by National Institutes of Health Grants 1-RO1 HD06104 and RR-59 from the General Clinical Research Centers Branch.

\section{REFERENCES}

1. Treloar, A. E., R. E. Boynton, B. G. Benn, and B. W. Brown. 1967. Variation of the human menstrual cycle through reproductive life. Int. J. Fertil. 12: 77-126.

2. Midgley, A. R., Jr., and R. B. Jaffe. 1968. Regulation of human gonadotropins. IV. Correlation of serum concentrations of follicle stimulating and luteinizing hormones during the menstrual cycle. J. Clin. Endocrinol. Metab. 28: 1699-1703.

3. Corker, C. A., F. Naftolin, and D. Exley. 1969. Interrelationship between plasma luteinizing hormone and œstradiol in the human menstrual cycle. Nature (Lond.). 222: 1063

4. Korenman, S. G., L. Perrin, B. Rao, and D. Tulchinsky. 1970. Plasma estrogen assays utilizing the cytoplasmic estrogen binder in rabbit uterus. Res. Steroids. 4: 287-296.

5. Tulchinsky, D., and S. G. Korenman. 1970. A radioligand assay for plasma estrone; normal values and variations during the menstrual cycle. J. Clin. Endocrinol. Metab. 31: 76-80.

6. Ross, G. T., C. M. Cargille, M. B. Lipsett, P. L. Rayford, J. R. Marshall, C. A. Strott, and D. Rodbard 1970. Pituitary and gonadal hormones in women during spontaneous and induced ovulatory cycles. Recent Prog. Horm. Res. 26: 1-48.

7. Vande Wiele, R. L., J. Bogumil, I. Dyrenfurth, M. Ferin, R. Jewelewicz, M. Warren, T. Rizkallah, and G. Mikhail. 1970. Mechanisms regulating the menstrual cycle in women. Recent Prog. Horm. Res. 26: 63-95.

8. Abraham, G. E., W. D. Odell, R. S. Swerdloff, and K. Hopper. 1972. Simultaneous radioimmunoassay of plasma $\mathrm{FSH}$, LH, progesterone, 17-hydroxyprogesterone, and estradiol-17 $\beta$ during the menstrual cycle. J. Clin. Endocrinol. Mctab. 34: 312-318.

9. Moghissi, K. S., F. N. Syner, and T. N. Evans. 1972. A composite picture of the menstrual cycle. Am. J. Obstet. Gynecol. 114: 405-418. 
10. Korenman, S. G., and B. M. Sherman. 1973. Gonadotropin and estradiol secretion during the preovulatory phase of the human menstrual cycle. J. Clin. Endocrinol. Metab. 36: 1205-1209.

11. Dignam, W. J., A. F. Parlow, and T. A. Daane. 1969. Serum FSH and LH measurements in the evaluation of menstrual disorders. Am. J. Obstet. Gynecol. 105: 679-693.

12. Strott, C. A., C. M. Cargille, G. T. Ross, and M. B. Lipsett. 1970. The short luteal phase. J. Clin. Endocrinol. Metab. 30: 246-251.

13. Yen, S. S. C., P. Vela, and J. Rankin. 1970. Inappropriate secretion of follicle-stimulating hormone and luteinizing hormone in polycystic ovarian disease. $J$. Clin. Endocrinol. Metab. 30: 435-442.

14. Boon, R. C., D. S. Schalch, L. A. Lee, and S. Reichlin. 1971. Plasma gonadotropin secretory patterns in patients with functional menstrual disorders and SteinLeventhal syndrome: response to clomiphene treatment. Am. J. Obstet. Gynecol. 112: 736-748.

15. Gambrell, R. D., Jr., R. B. Greenblatt, and V. B. Mahesh. 1973. Inappropriate secretion of $\mathrm{LH}$ in the Stein-Leventhal syndrome. Obstet. Gynecol. 42: 429440.

16. Sherman, B. M., and S. G. Korenman. 1974. Measurement of plasma LH, FSH, estradiol and progesterone in disorders of the human menstrual cycle: the short luteal phase. J. Clin. Endocrinol. Metab. 38: 89-93.

17. Sherman, B. M., and S. G. Korenman. 1974. Measurement of plasma $\mathrm{LH}, \mathrm{FSH}$, estradiol and progesterone in disorders of the human menstrual cycle: the inadequate luteal phase. J. Clin. Endocrinol. Metab. 39: 145149.

18. Odell, W. D., G. T. Ross, and P. L. Rayford. 1967. Radioimmunoassay for luteinizing hormone in human plasma or serum: physiological studies. J. Clin. Invest. 46 : 248-255.

19. Cargille, C. M., and P. L. Rayford. 1970. Characterization of antisera for human follicle-stimulation hormone radioimmunoassay. J. Lab. Clin. Med. 75: 1030-1040.

20. Korenman, S. G., R. H. Stevens, L. A. Carpenter, M. Robb, G. D. Niswender, and B. M. Sherman. 1974 Estradiol radioimmunoassay without chromatography: procedure, validation and normal value. J. Clin. Endocrinol. Metab. 38: 718-720.

21. Longcope, C. 1971. Metabolic clearance and blood production rates of estrogens in postmenopausal women. Am. J. Obstet. Gynecol. 111: 778-781.

22. Franchimont, P., J. J. Legros, and J. Meurice. 1972 Effect of several estrogens on serum gonadotropin levels in postmenopausal women. Horm. Metab. Res. 4: 288292.

23. Wise, A. J., M. A. Gross, and D. S. Schalch. 1973. Quantitative relationships of the pituitary-gonadal axis in postmenopausal women. J. Lab. Clin. Med. 81: 28-36.
24. Wallach, E. E., A. W. Root, and C.-R. Garcia. 1970. Serum gonadotropin responses to estrogen and progestogen in recently castrated human females. J. Clin. Endocrinol. Metab. 31: 376-381.

25. Ostergard, D. R., A. F. Parlow, and D. E. Townsend. 1970. Acute effect of castration on serum FSH and LH in the adult woman. J. Clin. Endocrinol. Metab. 31 : 43-47.

26. Yen, S. S. C., and C. C. Tsai. 1971. The effect of ovariectomy on gonadotropin release. J. Clin. Invest. 50: 1149-1153.

27. Goldenberg, R. L., J. M. Grodin, D. Rodbard, and G. T. Ross. 1973. Gonadotropins in women with amenorrhea: use of plasma follicle-stimulating hormone to differentiate women with and without ovarian follicles. Am. J. Obstet. Gynecol. 116: 1003-1012.

28. Yen, S. S. C., G. Vandenberg, and T. M. Siler. 1974. Modulation of pituitary responsiveness to LRF by estrogen. J. Clin. Endocrinol. Metab. 39: 170-177.

29. McCullagh, D. R. 1932. Dual endocrine activity of the testes. Science. (Wash. D. C.). 76: 19-20.

30. Howard, R. P., R. C. Sniffen, F. A. Simmons, and F. Albright. 1950. Testicular deficiency: a clinical and pathologic study. J. Clin. Endocrinol. Metab. 10: 121186.

31. McCullagh, E. P., and C. A. Schaffenburg. 1952. The role of seminiferous tubules in the production of hormones. Ann. N. Y. Acad. Sci. 55: 674-684.

32. Johnsen, S. G. 1964. Studies on the testicular-hypophyseal feed-back mechanism in man. Acta Endocrinol. Suppl. 90: 99-124.

33. Rosen, S. W., and B. D. Weintraub. 1971. Monotropic increase of serum FSH correlated with low sperm count in young men with idiopathic oligospermia and aspermia. J. Clin. Endocrinol. Metab. 32: 410-416.

34. Leonard, J. M., R. B. Leach, M. Couture, and C. A. Paulsen. 1972. Plasma and urinary follicle-stimulating hormone levels in oligospermia. J. Clin. Endocrinol. Metab. 34: 209-214.

35. Wieland, R. G., A. H. Ansari, D. E. Klein, N. S. Doshi, M. C. Hallberg, and J. C. Chen. 1972. Idiopathic oligospermia: control observations and response to cisclomiphene. Fertil Steril. 23: 471-474.

36. Paulsen, C. A. 1968. In discussion of R. S. Swerdloff and W. D. Odell, Some aspects of the control of secretion in (sic) $\mathrm{LH}$ and FSH in humans. In Gonadotropins. E. Rosenberg, editor. Geron-X, Inc., Los Altos, Calif. 163.

37. Van Thiel, D. H., R. J. Sherins, G. H. Myers, Jr., and V. T. De Vita, Jr. 1972. Evidence for a specific seminiferous tubular factor affecting follicle-stimulating hormone secretion in man. J. Clin. Invest. 51: 1009-1019. 